\title{
A potential role of the inferior frontal gyrus and anterior insula in cognitive control, brain rhythms, and event-related potentials
}

\author{
Mattie Tops ${ }^{1,2,3} *$ and Maarten A. S. Boksem ${ }^{4,5}$ \\ 1 Experimental Psychology, University of Groningen, Groningen, Netherlands \\ ${ }^{2}$ Centre for Child and Family Studies, University of Leiden, Leiden, Netherlands \\ ${ }^{3}$ Leiden Institute for Brain and Cognition, Leiden University Medical Center, Leiden, Netherlands \\ ${ }^{4}$ Donders Institute for Brain, Cognition and Behavior, Radboud University, Nijmegen, Netherlands \\ ${ }^{5}$ Rotterdam School of Management, Erasmus University, Rotterdam, Netherlands
}

\section{Edited by:}

Wim Notebaert, Ghent University, Belgium

Reviewed by:

Antonino Raffone, Sapienza

University of Rome, Italy

Wim Notebaert, Ghent University, Belgium

${ }^{*}$ Correspondence:

Mattie Tops, Centre for Child and

Family Studies, University of Leiden,

Post box 9555, 2300 RB Leiden,

Netherlands.

e-mail: topsm@fsw.leidenuniv.nl
In the present paper, we review evidence for of a model in which the inferior frontal gyrus/anterior insula (IFG/Al) area is involved in elaborate attentional and working memory processing and we present the hypothesis that this processing may take different forms and may have different effects, depending on the task at hand: (1) it may facilitate fast and accurate responding, or (2) it may cause slow responding when prolonged elaborate processing is required to increase accuracy of responding, or (3) it may interfere with accuracy and speed of next-trial (for instance, post-error) performance when prolonged elaborate processing interferes with processing of the next stimulus. We present our viewpoint that ventrolateral corticolimbic control pathways, including the IFG/AI, and mediodorsal corticolimbic control pathways, including dorsal anterior cingulate cortex areas, play partly separable, but interacting roles in adaptive behavior in environmental conditions that differ in the level of predictability: compared to dorsal feed-forward control, the ventral corticolimbic control pathways implement control over actions through higher responsiveness to momentary environmental stimuli. This latter control mode is associated with an attentional focus on stimuli that are urgent or close in time and space, while the former control mode is associated with a broader, more global focus in time and space. Both control pathways have developed extensively through evolution, and both developed their own "cognitive controls," such that neither one can be properly described as purely "cognitive" or "emotional." We discuss literature that suggests that the role of IFG/AI in top-down control is reflected in cortical rhythms and event-related potentials. Together, the literature suggests that the IFG/AI is an important node in brain networks that control cognitive and emotional processing and behavior.

Keywords: post-error slowing, post-conflict slowing, speed-accuracy trade-off, cognitive control, inferior frontal gyrus, anterior insula, event-related potentials, cortical rhythms

\section{INTRODUCTION}

Performance adjustments following conflict or erroneous responses, as well as changes in speed-accuracy trade-off, are regarded as examples of cognitive control and are most often ascribed to brain areas such as medial frontal cortex/anterior cingulate cortex (ACC) and dorsolateral prefrontal cortex. Although these performance adjustments have also been associated with activity in a ventrolateral prefrontal cortical area (that includes several sub-areas including the inferior frontal junction) that we will broadly refer to as inferior frontal gyrus/anterior insula (IFG/AI), such activity is often discounted as being related to motor inhibition or orienting responses, and not functionally meaningful or "cognitive." In the present opinion paper, we will present a model, and discuss evidence, suggesting that the IFG/AI is involved in elaborate attentional and working memory processing and present the hypothesis that this processing may take different forms and may have different effects, depending on the task at hand: (1) it may facilitate fast and accurate responding, or (2) it may cause slow responding when prolonged elaborate processing is required to increase accuracy of responding, or (3) it may interfere with accuracy and speed of next-trial (for instance, post-error) performance when prolonged elaborate processing interferes with processing of the next stimulus. Through this function, IFG/AI appears involved in minimizing interference effects in flanker and Stroop tasks, in slowing effects such as post-error slowing, post-conflict slowing, and in speed-accuracy trade-off.

Although we think there is converging support for this function of IFG/AI, we do not argue for a focus on the IFG/AI at the expense of investigation of the ACC, of interactions between areas including ACC and IFG/AI, or at the expense of more detailed characterization of areas within IFG/AI and ACC and their participation in brain networks. Rather, because functions of areas 
including dorsal ACC have more often been described as cognitive, while functions of IFG/AI, and the ventral corticolimbic control pathways it is part of (including also the amygdala), have often been described as emotional, in this paper we want to distil from the literature an emerging picture of IFG/AI contributions to cognition and focus on characterizing the cognitive control functions the IFG/AI might have. In doing so, we are guided by our viewpoint that ventral corticolimbic control pathways that include the IFG/AI, and dorsal corticolimbic control pathways that include dorsal ACC areas, are interacting but partly separable by their respective adaptations to environmental conditions that differ in the level of predictability (Tops et al., 2010). We will discuss that, in our opinion, both control pathways continued to develop during evolution, and both developed their own "cognitive controls," such that neither one can be properly described as "cognitive" nor "emotional" (Tops et al., 2010). More general and balanced discussions of theories and research of cognitive control and post-error adjustments can be found in other contributions to this Research Topic (e.g., Danielmeier and Ullsperger, 2011).

Increasing attention to the role of IFG/AI could have important implications and could facilitate future research in several directions. For instance, cognition and ACC function are increasingly being investigated in the context of psychopathology, mental health, and stress. However, the IFG/AI is among the areas that most consistently show increased activity related to anxiety and stress (see for a meta-analysis Etkin and Wager, 2007; for discussion Tops and Boksem, 2011).

In Section "Cognitive Control in the Brain," we will argue that IFG/AI has a relatively neglected role in cognitive control that is different from ACC. In Section "Cognition and Emotion in Dorsal and Ventral Corticolimbic Control Pathways" we will present our general model of ventral and dorsal control pathways and their role in cognition. In Section "The Role of IFG/AI in Cognitive Control" we focus on cognitive control functions of IFG/AI in the ventral control pathways, and how this function may be implicated in minimizing interference effects in flanker and Stroop tasks, in slowing effects such as post-error slowing, post-conflict slowing, and in speed-accuracy trade-off. In Section "Support for a Role of IFG/AI in Cognitive Control" we discuss evidence for involvement of IFG/AI in these interference and slowing effects. In Section "Long-Term Goals" we suggest that both ventral and dorsal control pathways can direct behavior toward long- and short-time goals, but in different ways. Finally, we discuss evidence suggesting that the role of IFG/AI in top-down control is reflected in cortical rhythms and event-related potentials.

\section{COGNITIVE CONTROL IN THE BRAIN}

Functional neuroimaging studies suggest that dorsal ACC plays an important role in cognitive control. This brain area is reliably activated when tasks require the ongoing adjustment of the allocation of attention. The ACC has come to occupy a central role in theories of attention and cognitive control, which hold that the ACC either monitors response conflict, signaling the need for adjustments in cognitive processes, or directly mediates such adjustments (e.g., Botvinick et al., 2001). However, it has been shown that subjects with damage to the dorsal ACC show normal adjustments in performance following manipulations in response conflict in both Stroop and go-no-go tasks. Furthermore, damage to the ACC did not impair performance on anterior attention tasks, post-error slowing, nor the ability to adjust performance in response to explicit speed or accuracy instructions, arguing against a necessary role for the ACC in these processes (Fellows and Farah, 2005; Baird et al., 2006).

A study in which the ACC was lesioned in monkeys, showed that the ACC is not involved in detecting or correcting errors, but in guiding voluntary behavior based on the history of actions and outcomes (Kennerley et al., 2006). ACC lesions did not impair the performance of the monkeys immediately after errors, but made them unable to integrate rewards and punishments over multiple trials to guide the continuation of behavior. But if the ACC is not involved in next-trial response-adjustments, this means that this kind of computations and behavioral control is performed elsewhere, and that the outcomes of such computations are forwarded to the ACC, in order to be integrated over multiple trials, guiding the choice of a general behavioral set and level of engagement. Interestingly, in a recent fMRI study dorsal ACC activity was not sensitive to Stroop congruency, error likelihood, or response conflict after controlling for increased brain activity with timeon-trial, suggesting that the greater ACC activity on incompatible trials may stem from longer reaction times rather than response conflict; however, left IFG activity was correlated with increased Stroop congruency effects (Grinband et al., 2011). There is discussion about the study of Grinband et al. (Yeung et al., 2011), and there appears to be evidence for involvement of rostral ACC in next-trial cognitive control (di Pellegrino et al., 2007). Our intention is not to argue against ACC involvement in next-trial cognitive control, but to highlight potential IFG/AI contributions.

There is growing support for, and attention to, the role of IFG/AI pathways in executive functions such as post-error slowing that have so far largely been ascribed to the ACC-prefrontal cortical circuit, and recognition of the involvement of orienting responses in such functions (Tucker et al., 2003; Tops, 2004; Brass et al., 2005; Tops et al., 2006, 2010; Boksem et al., 2008; Eckert et al., 2009; Notebaert et al., 2009; Tops and Boksem, 2010, 2011; Ullsperger et al., 2010; Ide and Li, 2011). Where less then 10 years ago strong activation of the IFG/AI was regarded of no importance, and in an astonishing number of cases was reported without comment, an extraordinary convergence of evidence has since prompted authors to describe this area as the integral hub and convergence zone between networks that control behavior in low-predictable environments (Bossaerts, 2010; Craig, 2010; Menon and Uddin, 2010; Nelson et al., 2010; Tops et al., 2010; Higo et al., 2011). Likewise, while classically considered a limbic region, recent evidence from network analysis suggests a critical role for the IFG/AI in high-level cognitive control and attentional processes (Craig, 2010).

\section{COGNITION AND EMOTION IN DORSAL AND VENTRAL CORTICOLIMBIC CONTROL PATHWAYS}

Research investigating the evolution and ontogeny of the prefrontal cortex suggests that the lateral prefrontal cortex initially emerged from ventrolateral prefrontal regions, followed by dorsolateral and then anterolateral cortices (Flechsig, 1901, 1920; Fuster et al., 1997). We previously argued that evolution did not lead to the 
development of separate brain systems for emotion vs. cognition, but did lead to the development of partially separate ventrolateral and mediodorsal control pathways sustaining behavioral programs adapted to different environments (Tops et al., 2010). We previously described how the distinction between ventrolateral and mediodorsal control pathways can be applied to literatures about temperament, personality, emotion, and psychopathology (Tops et al., 2010). However, the theory of Tucker and Luu from which it was developed has also been applied to cognitive control (e.g., in the empirical work of Luu and Tucker) and the modulation by emotion of the width of attention (reviewed by Friedman and Förster, 2010). In Figure 1 we present a model of our hypothesis regarding how the ventral and dorsal control pathways are implicated in cognitive control, with a relative focus on the often neglected ventral controls.

In short, the revised model of Tucker and colleagues (Tops et al., 2010) proposes that two types of brain systems developed during evolution. One type was adapted to control cognition and behavior in high-predictable environments. These systems control behavior guided by context models; models that are formed in long-term memory by the predictability of the environment/context. The other type of system was adapted to control cognition and behavior in low-predictable environments. In low-predictable environments, effective context models can not be formed nor used to control behavior in adaptive ways. Instead, behavior is guided reactively by momentary feedback control by environmental stimuli. This reactive guidance by momentary environmental stimuli is associated with attentional focus on stimuli that are urgent and close in time and space. Those stimuli can be positive ("I have to catch that reward that is in my reach before it gets away") or negative ("I have to get away from that danger before it gets me, because I'm in its reach"). The reactive systems are involved in, and relate stimuli to, the experienced self in the here and now. In contrast, there is less urgency and focus on the moment (i.e., broader, more global focus in time and space) when behavior is guided proactively (in feed-forward fashion) by context models. Playful exploration of the environment may be stimulated by this type of control, to support the construction and updating of context models.

Friedman and Förster (2010) reviewed literature showing that positive emotional states and implicit affective cues expand (global focus), and that negative emotional states and implicit affective cues constrict (local focus), the scope of attention on both the perceptual and conceptual level. They concluded that a large and growing body of research supports the model and assumptions that originated from Tucker's work. Starting with Tucker's neuropsychological theory (e.g., Tyler and Tucker, 1982; Tucker and Williamson, 1984; Derryberry and Tucker, 1994; Luu et al., 1998), early studies were collectively inspired by a set of converging empirical and theoretical contributions (e.g., Schwarz, 1990; Tucker et al., 1995; Fredrickson, 1998). Friedman and Förster also discussed recent findings and ideas by Harmon-Jones and Gable, which, as an exception, did not appear to fit the theoretical framework. These authors reported several studies in which reactive positive (appetitive, e.g., hunger) reward motivation facilitated a

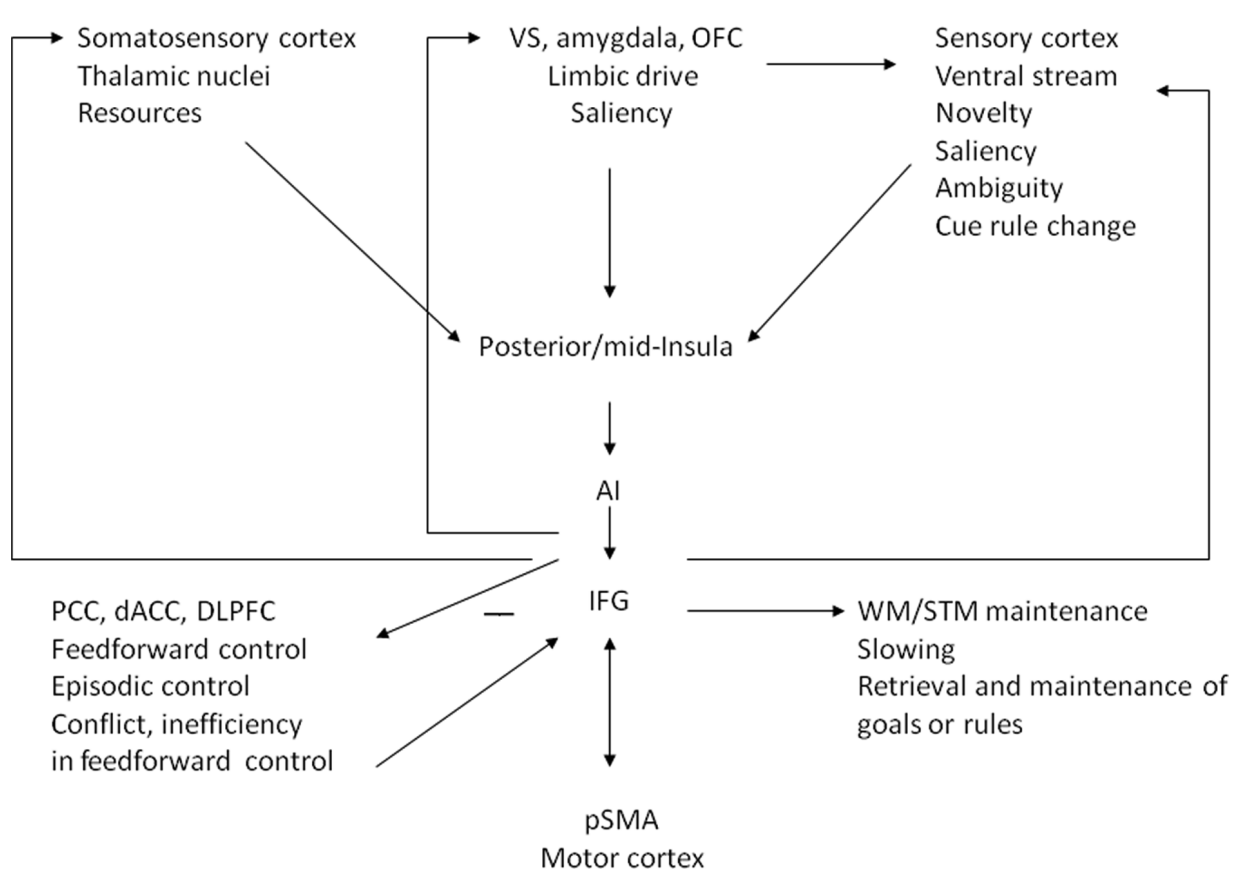

FIGURE 1 | Schematic depiction of the roles of ventral and dorsal corticolimbic control pathways in cognitive control, focusing on ventral control. At the level of the IFG/Al interoceptive, limbic emotion-motivational, and sensory inputs are integrated. IFG/Al connects back to somatosensory, limbic, and sensory/attentional orienting areas to regulating the level of activation of representations that are relevant for response selection. IFG/AI may also keep the representations and goals active as part of maintenance working memory function. IFG, inferior frontal gyrus; Al, anterior insula; VS, ventral striatum; OFC, orbitofrontal cortex; $\mathrm{PCC}$, posterior cingulate cortex; $\mathrm{dACC}$, dorsal anterior cingulate cortex; dlpfc, dorsolateral prefrontal cortex; pSMA, presupplementary motor area; WM, working memory; STM, short-term memory. 
local focus (Gable and Harmon-Jones, 2008; Harmon-Jones and Gable, 2009). Although the attempt by Friedman and Förster to reconcile the ideas of Gable and Harmon-Jones with their own ideas and the general framework figured prominently in their original review article, Harmon-Jones et al. (2011b) published a comment in Psychological Bulletin proposing an alternative model to explain the findings. However, in their reply, Friedman and Förster (2011) argue that the alternative model fails to establish a compelling alternative explanation for the multitude of specific findings they reviewed. Interestingly and importantly, the revision and update of Tucker's model we published last year actually prominently discussed the findings of Gable and Harmon-Jones to explain how small revisions to the original model increase the explaining power and fit to the literature (Tops et al., 2010).

The revised model retains the hypothesis that the systems associated with the context models are biased toward positive emotion, optimism, self-efficacy, and confidence, because the context models are based on previous predictive success and positive outcomes. However, one adjustment is the addition of a reactive system with a narrow focus in space and time on obtaining rewards, in addition to the reactive system with a narrow focus in space and time on avoiding punishment or harm. This additional appetitive reactive reward-oriented system incorporates the findings (local focus when reactive reward motivation is stimulated) and ideas of Harmon-Jones et al. (2011b) within the broader framework that was built from Tucker and colleagues's original work. Moreover, it also seems to incorporate findings with other outcome measures in the research by Förster and colleagues (e.g., Förster, 2009; Liberman and Förster, 2009). They found that a global attentional focus was associated with larger psychological distances in time and space, "promotion focus," high power and a focus on similarities (which is compatible with the formation of context models), while a local attentional focus was associated with small psychological distances in time and space, "prevention focus," low power and a focus on differences.

According to the self-regulation theory of Higgins (1997), a promotion focus guides behavior according to ideals and aspirations, while a prevention focus guides behavior according to "oughts" such as safety and responsibilities. Interestingly, a recent theory of reasoning and decision making proposes that dorsolateral prefrontal cortex represents behavior-guiding principles for evaluating the permissibility or fairness of observed behavior while social norms for necessary (obligatory or prohibited) courses of action are represented by ventrolateral prefrontal cortex (Barbey et al., 2009). Promotion relative to prevention focus has been associated with perceptions of power and predictability (e.g., Langens, 2007). Behavior control by social norms for necessary courses of action in ventrolateral prefrontal cortex may have developed from its attentional focus on stimuli that are urgent and close in time and space, while reflection on ideals, permissibility, and fairness may be allowed for when there is less urgency and focus on the moment and may involve activation of context models. Barley et al. argue that, from an evolutionary perspective, the emergence of lateral prefrontal cortex subregions reflects their relative priority for the formation of organized social groups. Furthermore, consistent with its evolutionary development, the ontogeny of the lateral prefrontal cortex reflects the importance of first representing social norms for necessary behavior (i.e., fundamental rules the child must obey), followed by an understanding of permissible courses of action (e.g., guided by judgments of equity and fairness), and finally high-order inferences involving both forms of representation (Barbey et al., 2009). The work by Barbey et al. (2009) may extend our model to the realm of higher order processing such as social reasoning and decision making, and inductive and deductive inference making.

The present model seems related to the well-known hypothesized distinction between ventral and dorsal posterior visual processing streams specialized respectively in processing of "what" and "how" information (Goodale and Milner, 1992). According to Goodale and Milner, the dorsal pathway extracts visual signals relevant for driving automatic or feed-forward motor behavior (perception for action), whereas the ventral pathway extracts information relevant for identification and other forms of semantic knowledge. It has been suggested that these processing streams are extended toward frontal ventral and dorsal areas that feed back to implement cognitive control (Sakagami et al., 2006; O'Reilly, 2010). Ventrolateral prefrontal cortex (IFG/AI) mediates active maintenance of stimulus information, and this produces a topdown biasing effect to drive selection and retrieval dynamics in posterior cortex. On the other hand, one should expect to see dorsolateral prefrontal cortex activation whenever the dorsal parietal cortex requires extra cognitive control (such as working memory and top-down biasing) to carry out the processing of sensory information to guide action outputs (O'Reilly, 2010; cf. Sakagami et al., 2006). Although similar, compared to this account our model seems more integrative, associating ventral and dorsal systems with behavioral programs that include motivation, emotion, viscerosensation, and memory (Tops et al., 2010).

Figure 1 shows that at the level of the IFG/AI interoceptive, limbic emotion-motivational, and sensory inputs are integrated (Craig, 2008, 2009). Based on reviews of these and other findings, Craig reasoned that in the IFG/AI an integrated representation is formed of the global emotional moment, i.e., that awareness of the immediate moment is formed. Also in our model, the IFG/AI is an integration and control node in ventral networks that implement "immediate" reactivity to sensory stimuli, and "immediate" connection between sensory processing and action control. Adapted to low-predictable environments, ventral control applies a narrow spatial (target-focused) and temporal (immediate moment) focus to processing, action control, and awareness (cf. Craig, 2009). In contrast, adapted to predictable environments, dorsal control applies a wider spatial and temporal focus, which allows for recruitment of context models, and sustained control over behavioral episodes according to information conveyed by temporally remote events and history of actions and outcomes, and implementation of feed-forward control of behavioral patterns and integrated action sequences (Heidbreder and Groenewegen, 2003; Kennerley et al., 2006; Kouneiher et al., 2009). The wider temporal focus produces awareness that includes a sense of past and future. Notice that quite differently from reactive ventral control, feedforward implementation, and execution of action sequences may be facilitated by suppressing ongoing processing of sensory input that might disrupt motor output (Jacobs and Fornal, 1995). 
Classical work showed that affective arousal states carry resource information (physiological resources such as glucose levels and the condition of muscles, as well as social resources) and are associated with implicit perceptions of coping abilities (Thayer, 1989). Only in low-predictable environments it is necessary to have a continuous readout of the level of available resources to constrain immediate action. In the IFG/AI information about the level of resources is combined with emotional or "drive" information that biases the direction of action either toward (approach, e.g., craving, hunger, love, trust) or away from (avoidance, e.g., disgust, pain, distrust) a target object (Tops and de Jong, 2006; Tops et al., 2010). This directional drive property may have been derived from functions of the gustatory cortex that is situated in the insula. The directional drive bias and resource information is furthermore combined with relevant target information and, depending on circumstances, priming or preparation of responses and matching autonomic responses (Heidbreder and Groenewegen, 2003). Together, the continuous readout of drive direction bias, resource level, and orienting toward potential targets enable fast, opportunistic action at the spur of the moment. In other words, it may enable us to catch a reward that is in our reach before it gets away and to get away from a danger before it gets us, when we are in its reach. In contrast, in predictable environments dorsal control enables fast and efficient action by means of feed-forward action control and guidance by context models.

In many situations and for many tasks, dorsal, and ventral systems will collaborate and interact in the control of behavior. For instance, support has been found for interactions between IFG and dorsal frontal areas, where IFG implements reactive (momentary) immediate action according to the information conveyed by concomitant contextual signals, while dorsal frontal areas implement "proactive" episodic motivation control: sustained control over behavioral episodes according to information conveyed by temporally remote events (or context models) and history of actions and outcomes, and implementation of feed-forward control of behavioral patterns and integrated action sequences (Heidbreder and Groenewegen, 2003; Kennerley et al., 2006; Kouneiher et al., 2009). However, temporary or relatively stable biases toward reactive control may result from temperament, unpredictable dangerous or urgent situations, perceptions of unpredictability after trauma or inconsistent parenting, and interactions between those. In contrast, bias toward context model-guided control may relate to temperament or follow consistent parenting and predictable, secure early environments that favored exploration and the development of context models (i.e., internal working models, in terms of Bowlby's (1988) attachment theory).

The input and feedback to IFG/AI and back to somatosensory, limbic and sensory/attentional orienting areas as depicted by arrows in Figure 1, fit the consistent implication of IFG/AI activity in somatosensory working memory (e.g., Auksztulewicz et al., 2011), anxiety, and somatic complaints (Paulus and Stein, 2006; Etkin and Wager, 2007; Tops and Boksem, 2011). We suggest that during evolution cognitive control areas have developed that are basically control areas involved in temperament, emotion regulation, and stress responding (Cromwell and Panksepp, 2011), but now also implicated in cognitive task performance. Hence, we think the model in Figure $\mathbf{1}$ can be applied to temperament, emotion regulation, stress responding, as well as to cognitive control. However, the next sections of this paper will focus on the involvement of the connections between IFG/AI and the ventral processing stream in cognitive control.

\section{THE ROLE OF IFG/AI IN COGNITIVE CONTROL}

In Figure 1, the feedback connection between IFG/AI and ventral sensory cortex is meant to illustrate the role of IFG/AI in regulating the level of activation of representations in posterior brain areas that are relevant or irrelevant, respectively, for response selection (Higo et al., 2011). In other words, those connections have a role in the coordination of focal elaborate processing of target stimuli; focal in time and space. Depending on the requirements of the task at hand, these connections together with output to motor cortex allow for tight feedback control of action. This means that IFG/AI is involved both in monitoring target or cue events and in updating the corresponding action plan. One example that supports such a combination of functions is a study that combined the causal methodology of reversible cortical interference (transcranial magnetic stimulation) with an experimental task that measured different types of updating. This study found that the right inferior frontal cortex can be functionally segregated into two subregions: an inferior frontal junction region that seems critical for visual detection of changes in the environment, and a more ventral IFG region, which updates the corresponding action plan (Verbruggen et al., 2010).

However, if the target stimulus is removed before (elaborate) processing is finished, processing may proceed on a short-term memory representation of the target or sensory input. Much has been learned over the last two decades on where in the brain working memory functions are carried out. Much less is known on how the brain accomplishes short-term maintenance and goal-directed manipulation of information. One view proposed a functional distinction, arguing that ventrolateral areas are mostly involved in pure maintenance of information and keeping representations active without external input, whereas dorsolateral areas are more involved in tasks requiring some processing of the memorized material (Owen, 2000). The IFG appears to project back to the temporal lobe to keep target/object representations active (Assadollahi and Rockstroh, 2008) and may do so through mechanisms of synchronization of neuronal firing (cf. Hommel et al., 2006). We suggest that similar feedback connections may be implicated both in regulating the level of activation of representations in posterior brain areas that are relevant to prevent interference from irrelevant simultaneous representations, and in regulating the level of activation of representations in posterior brain areas that are relevant to prevent decay or interference from subsequent representations. However, as we are not aware of much evidence for this suggested mechanism, we leave the exact mechanism of short-term memory or maintenance working memory in the IFG/AI open.

Both prolonged focus on, and processing of, potentially ambiguous or relevant target representations that are still updated in sensory cortex, and prolonged processing of targets that have been removed from input channels, constitute what has been called a "redundancy bias" to processing in ventral systems (Tucker et al., 1995). Importantly, although both operations exclude the continuous stream of sensory input largely or completely from 
momentary awareness, momentary awareness itself is continued with focus on the target. That is, if processing is performed on a short-term memory representation, the "emotional moment" (Craig, 2009) constitutes of outcomes of this processing in IFG/AI and simultaneous inputs such as limbic drive and somatosensory inputs.

Prolonged processing of targets that have been removed from input channels (or replaced or updated) places that target in momentary awareness, and excludes subsequent stimuli and targets from momentary awareness for the duration of this prolonged processing. This may cause interference with IFG/AI mediated processing and momentary awareness of stimuli following targets in rapid serial visual presentation tasks and following stimulus events that would trigger prolonged elaborate processing in speeded reaction time tasks, such as performance errors, incongruent flankers, novelty, saliency, ambiguity, or cues of rule change (Figure 1). We think that this interference with the processing of subsequent stimuli is involved in post-error slowing and post-conflict slowing.

We leave open whether control from the IFG/AI involves any active inhibition of processing or action, or only activation of representations (input or behavior) that compete with other representations, which has been suggested to be a more parsimonious explanation of IFG/AI functions (Hampshire et al., 2010). In terms of visual processing, inhibition of one object when attention is focused on another can be explained as a secondary effect, i.e., an emergent property of local competition when one competing item is subjected to top-down potentiating signals which have their source in the IFG/AI and may reflect willful focusing of attention (Hampshire et al., 2010). However, this leaves the possibility that motor programs of immobility or behavioral inhibition are part of innate stimulus - response programs or are often used and therefore primed in certain individuals (Tops and Boksem, 2011).

Similarly, we will not discuss extensive evidence that IFG/AI may inhibit processing of emotional stimuli in sensory cortex, memory, and limbic areas. Although this literature is too extensive and complicated to discuss within the scope of this paper, we will mention a few examples, because we think emotion control by the IFG/AI may involve mechanisms that are similar to, and may overlap with, those implementing cognitive control. In one study, anticipatory bilateral IFG/AI activation before picture presentation was inversely correlated with superior temporal gyrus (STG) activation during presentation of scary pictures in anxiety prone individuals, suggesting that IFG/AI activation suppressed the sensory representation in STG (Simmons et al., 2006). According to another study, emotional memories are initially suppressed by the right IFG over regions supporting sensory components of the memory representation (visual cortex, thalamus; Depue et al., 2007). One explanation for these findings is that the right IFG is engaged in a coping strategy - for example retrieving an alternative thought, image, or memory in order to swamp limited capacity processing resources (Hampshire et al., 2010). Wager et al. (2008) identified a right IFG/AI region whose activity correlated with reduced negative emotional experience during cognitive reappraisal of aversive images. They then applied a pathwaymapping analysis on subcortical regions to locate mediators of the association between IFG/AI activity and reappraisal success (i.e., reductions in reported emotion). They identified two separable pathways that together explained approximately $50 \%$ of the reported variance in self-reported emotion: (1) a path through nucleus accumbens that predicted greater reappraisal success, and (2) a path through ventral amygdala that predicted reduced reappraisal success (i.e., more negative emotion). These results provide direct evidence that IFG/AI is involved in both the generation and regulation of emotion through different subcortical pathways. Maybe this result means that the right IFG is involved in the passive coping strategy of emotion-focused coping by amplifying positive vs. negative emotions.

\section{SUPPORT FOR A ROLE OF IFG/AI IN COGNITIVE CONTROL FLANKER INCONGRUENCY EFFECTS AND SPEED-ACCURACY TRADE-OFF}

The right IFG/AI may have an alarm/orienting function as part of its critical role in the switching between internally and externally oriented control modes in response to salient stimuli (Sridharan et al., 2008). Furthermore, the IFG/AI may coordinate and participate in further processing of salient and/or ambiguous stimuli. Leitman et al. (2010) showed that increased saliency of emotion-specific acoustic cues was associated with increased activation in key components of the ventral emotional/attentional system including STG, insula, and amygdala, whereas decreased saliency of acoustic cues was associated with increased IFG activity and IFG-STG connectivity. These results suggest that sensoryintegrative processing that is central in emotional intensity and attentional absorption is facilitated when the stimulus is rich in affective information, yielding increased activation in temporal cortex and amygdala. Conversely, when the stimulus is ambiguous, greater evaluative processes are recruited, increasing activation in IFG, and IFG-STG connectivity (Leitman et al., 2010).

Incongruency in a flanker task activates the IFG/AI and underlying striatum area, and although the direction of the relationship is inconsistent over studies, activity in this area was in some studies correlated with the flanker incongruency effect on reaction times (Bunge et al., 2002; Wager et al., 2005); a relationship was also found with the incongruency effect on reaction times during a Stroop task (Melcher and Gruber, 2008). The IFG/AI-ACC network is thought to be involved in incongruency detection or resolving, and/or in inhibitory processes that dampen the tendency to make an inappropriate response (e.g., Aron et al., 2004; Wager et al., 2005). The IFG/AI is active across tasks involving incongruency, inhibition or working memory (including the flanker, go/no-go, stop signal, stimulus-response compatibility, Simon, Stroop, and spatial- and verbal-working memory tasks; Nee et al., 2007; McNab et al., 2008) including tasks involving semantic or emotional incongruency that elicit the N400 evoked potential (Maess et al., 2006; Van Petten and Luka, 2006), consistent with a role of this area in a bias to working memory or attention that increases processing of ambiguous stimuli. The IFG/AI also consistently shows error-related activity (Wittfoth et al., 2008) which may reflect increased processing after erroneous responses. Moreover, a meta-analysis suggested that there is an asymmetry in the activation of the IFG/AI, left IFG/AI showing larger activation by flanker incongruency and right IFG/AI by errors (Ullsperger et al., 2010). 
Flanker incongruency effects depend on speed-accuracy strategy, the effects being larger when speed is stressed (Wylie et al., 2009). The speed and accuracy of decision making have a wellknown trading relationship: hasty decisions are more prone to errors while careful, accurate judgments take more time. Using functional magnetic resonance imaging (fMRI), Ivanoff et al. (2008) showed that emphasizing the speed of a perceptual decision at the expense of its accuracy lowers the amount of evidencerelated activity in the IFG/AI that is gathered before responding. Moreover, this speed-accuracy difference in activity correlated with a behavioral measure of speed-accuracy difference in decision criterion. Thus, the IFG seems involved in elaborate attentional and working memory processing that may facilitate fast and accurate responding or slow responding in the case of prolonged elaborate processing to increase accuracy of responding.

\section{POST-ERROR SLOWING}

It has been reported that post-error slowing was larger when instruction stressed accuracy rather than speed (Jentzsch and Leuthold, 2006; Danielmeier and Ullsperger, 2011). In a study by Dudschig and Jentzsch (2009), post-error slowing was found to be increased and performance more error-prone with a decreasing response-stimulus interval, providing evidence for the idea that error evaluation can produce substantial interference with subsequent trial processing, particularly when there is insufficient time between the error and the subsequent event. Whereas response-stimulus-intervals were varied block-wise in the study by Dudschig and Jentzsch, their result was replicated in a study that varied response-stimulus-intervals trial-to-trial (Danielmeier and Ullsperger, 2011). EEG alpha power during task performance was recently shown to display error-related and incongruency-related changes (Carp and Compton, 2009; Compton et al., 2011). While alpha suggested temporary disengagement after correct responses, after errors there appeared to be a failure to disengage which predicted post-error slowing. Indeed, depression is associated with a decrease in accuracy, increased slowing and inability to disengage after errors (Tucker et al., 2003; Compton et al., 2008) and error-related negativity (ERN) ERP amplitude predicted posterror slowing only among depressed participants in an emotional Stroop task condition involving negative words (Compton et al., 2008), suggesting a relationship in depression between slowing and failure to disengage. Interestingly, color-naming reaction time interference effects by threat stimuli in the emotional Stroop, which has been associated with anxiety in numerous studies, also appear to reflect slow disengagement from the previous trial, similar to what seems to be happening in post-error slowing (Phaf and Kan, 2007). See for a discussion of the relation between post-error slowing and anxiety, arousal, and orienting responses, Notebaert et al. (2009) and Tops and Boksem (2011).

Unpublished results of a recent study (Tops and Boksem, 2010) in which subjects performed the Eriksen flanker task for $2.5 \mathrm{~h}$, support that post-error processing may interfere with accurate nexttrial performance when prolonged elaborate processing interferes with processing of the next stimulus. Over the whole group of subjects, post-error slowing was only significant in the first interval of the experiment (first $20 \mathrm{~min}$ ), and parallel to increasing reaction times, post-error accuracy in the first intervals switched to post-error inaccuracy in the last interval (i.e., the last $20 \mathrm{~min}$ ). Moreover, in the first interval, the only interval that showed both significant post-error slowing and post-error accuracy, post-error accuracy was correlated with shorter reaction times. After controlling for reaction times, post-error slowing predicted post-error accuracy. This suggests that only when reaction times were short the response-stimulus interval was long enough to benefit from the post-error processing, while when post-error processing added up to longer overall reaction times, there was interference of posterror continued engagement with the last trial with processing and performance in the subsequent trial.

In contrast, in a task in which an error on a difficult "lure" trial predicted that the same lure would be repeated between two and seven trials later, such that effects of post-error failure to disengage were unlikely to interfere with performance on the next lure trial, post-error slowing was related to increased accuracy on the next lure trial; the slowing and the increased accuracy were predicted by activity in right IFG/AI, middle frontal gyrus, and ACC (Hester et al., 2007). Right IFG activation is related to post-error slowing after errors (Marco-Pallarés et al., 2008; King et al., 2010) and after failures to inhibit responding (Li et al., 2008) and lesions of the right inferior frontal sulcus reduced post-error slowing (Molenberghs et al., 2009). A correlation has been found between individual differences in post-error slowing and white matter integrity beneath dorsal ACC regions that are connected to the right IFG (Danielmeier et al., 2011).

In conclusion, post-error processing may be associated with increased post-error accuracy, if conditions are such that posterror processing does not interfere with performance in the post-error trial. There are indications that prolonged processing in the IFG/AI is involved in post-error slowing and either post-error accuracy or post-error interference, depending on response-stimulus timing.

\section{POST-CONFLICT SLOWING}

Verguts et al. (2011) recently reviewed and "introduced" the phenomenon of post-conflict slowing. Previous studies suggested that following incongruent trials subjects slow responses on the subsequent trials when task conditions trigger the need for the allocation of attentional control, such as in the case of high conflict, perceptual ambiguity, or difficult tasks (Ullsperger et al., 2005; Bugg, 2008; Verguts et al., 2011). This post-conflict slowing has been interpreted as reflecting a speed-accuracy trade-off (Ullsperger et al., 2005). Indeed, in our study mentioned in the previous section (Tops and Boksem, 2010) more post-conflict slowing correlated with a speed-accuracy bias toward accuracy, as well as with less flanker congruency effect on accuracy (unpublished results).

Because post-conflict slowing is a less-described phenomenon (Verguts et al., 2011), we will present an analysis of this effect from our previous study (Tops and Boksem, 2010). We performed a General Linear Model analysis of reaction times with as withinsubject factors flanker congruency, post-incongruency (i.e., previous trial was a congruent vs. incongruent trial). There was a main effect of post-incongruency $[F(1,23)=42.83, p<0.0001]$ showing that reaction times were longer when the previous trial was incongruent $(M=488, \mathrm{SD}=64)$ than when the previous trial was congruent $(M=478, \mathrm{SD}=60)$. A similar analysis 
of proportion correct responses found a main effect of postincongruency $[F(1,23)=6.01, p<0.05]$ showing that proportion correct responses was higher when the previous trial was incongruent $(M=0.924, \mathrm{SD}=0.034)$ than when the previous trial was congruent $(M=0.911, \mathrm{SD}=0.044)$. Post-incongruency increase in accuracy correlated negatively with reaction times $(r=-0.62$, $p<0.001)^{1}$.

\section{LONG-TERM GOALS}

In proactive systems context models can assist in directing behavior toward long- and short-time goals. In reactive systems goals and motivational stimuli can be held active by redundant attentional and working memory processing and actually lead to perseveration or obsessional behavior and rumination (Tucker et al., 1995; Tops et al., 2010). We adhere to the view that mediodorsal areas implement sustained episodic motivation control over behavioral episodes (Kouneiher et al., 2009), guiding voluntary behavior based on the history of actions and outcomes (Kennerley et al., 2006), and context models. When action outcomes are unfavorable and/or context models suggest it is better to stop the particular endeavor, and do what "experience has taught you is best for you," the endeavor will be abandoned in favor of flexible and adaptive switching to alternative endeavors or exploration. However, adapted to low-predictable environments, the ventrolateral prefrontal cortical controls of reactive systems may persevere on a potential opportunity to exploit (Tops et al., 2010). Maintenance of drive, and retrieval and/or maintenance of goals in working memory may keep goals active over time and in the face of resistance and help to implement effortful control of behavior in the service of long-range goals.

We sometimes use the label "proactive" to refer to the feedforward and context model-guided action control by the dorsal systems. We think that the labels "proactive" and "reactive" may help us connecting to an audience of social and clinical psychologists. However, the functions of the systems cannot be derived from the labels, and the labels can even cause confusion. Elaborate processing of stimuli in working memory at the expense of subsequent stimuli may not seem "reactive" in some sense. Keeping goals active in working memory seems to be part of what other researchers called "proactive" or goal-directed, and contrasted with reactive, stimulus or cue-driven control (Dosenbach et al., 2007; Braver et al., 2009; Aron, 2011). It is convenient and necessary to sometimes use short labels to express which systems or parts of the model are referred to, but no labels can capture the complexities of the systems, and it is important not to derive system function simply from the labels.

Elsewhere (Tops et al., 2010) we discussed how the combination of a reactive approach system, a reactive avoidance system, and a proactive or context model-guided system produces a model that is very similar to a model that has recently been proposed to integrate literatures on temperament and self-regulation systems, neuromodulatory function of serotonin, psychopathology,

\footnotetext{
${ }^{1}$ Notice that, because reaction time flanker incongruency effects decrease with increasing reaction times (in our study: $r=-0.44, p<0.05$ ), post-conflict slowing may cause a spurious conflict-adaptation-like effect (i.e., a decreased incongruency effect following incongruent trials).
}

and neuroimaging studies of dorsal vs. ventral cortical function (Carver et al., 2008, 2009). The model of Carver et al. was inspired by the work of Mary Rothbart and Michael Posner on the development of attention systems. We discussed the advantages of our approach, and the need to distinguish between the dorsal system on the one hand, and the controls that developed during evolution in each of the ventral and dorsal systems on the other hand. Related to this, we argued against the meaningfulness of an emotion-cognition distinction: although dorsal context modelguidance systems may on first intuition appear more cognitive compared to ventral reactive systems, each of them involves motivation and emotion and controls that continued to develop during evolution. And both dorsal and ventral control areas are implicated in aspects of sustained performance control and task sets (Dosenbach et al., 2007).

Additionally, the ventral cortical systems may have specialized slightly differently in each hemisphere (Tops and Boksem, 2010). We speculate that, at least relatively, in the left hemisphere the ventrolateral pathways involved in cognitive control elaborated to specialize in keeping goals active (reflecting in constraint, persistence, determination; Schiff et al., 1998; Bunge et al., 2003; Gusnard et al., 2003; Whittle et al., 2006; Stuss and Alexander, 2007; Li et al., 2008; Harmon-Jones et al., 2011a; cf. Bernal and Altman, 2009; O'Reilly, 2010), while in the ventrolateral pathways in the right hemisphere cognitive control elaboration specialized in intense attentional absorption in the moment and keeping targets active (Hampshire et al., 2009; Nelson et al., 2010; Higo et al., 2011). This may be why in the left hemisphere the IFG/AI displays stronger connections with dorsolateral prefrontal cortex and bilateral supplementary motor area while in the right hemisphere the IFG/AI displays stronger connections with the rostral ACC, STG, and occipital cortex (Cauda et al., 2011).

\section{ORIENTING AND IFG/AI TOP-DOWN CONTROL REFLECTED IN fMRI, EEG, AND ERPs IFG/AI TOP-DOWN CONTROL REFLECTED IN fMRI}

The right IFG/AI may have an alarm/orienting function as part of its critical role in the switching between internally and externally oriented control modes in response to salient stimuli (Sridharan et al., 2008). Moreover, the IFG/AI appears to exert top-down control over sensory areas including STG or sulcus (STS) to coordinate focal elaborate processing of target stimuli (Frye et al., 2010; Leitman et al., 2010; Zanto et al., 2010; Chadick and Gazzaley, 2011; Higo et al., 2011), functional correlations being positive or negative, depending on which stimulus is to be attended, and which ignored (Higo et al., 2011). For example, the results of Leitman et al. (2010) suggested that sensory-integrative processing is facilitated when the stimulus is rich in affective information, yielding increased activation in STS and amygdala. Conversely, when the stimulus is ambiguous, greater evaluative processes are recruited, increasing activation in IFG and IFG-STS connectivity. As another example, functional connectivity analysis of human fMRI data revealed that visual cortical areas (fusiform face area and parahippocampal place area) that selectively process task goal relevant information are functionally connected with the ventral attentional system areas including bilateral inferior frontal junction, whereas those that process irrelevant context information are 
simultaneously but dissociatably coupled with the "default mode network" part of the dorsal system, which is activated by prospective/retrospective memory. This indicates that sensory cortical regions are differentially and dynamically coupled with distinct networks on the basis of task goals (Chadick and Gazzaley, 2011).

\section{IFG/AI TOP-DOWN CONTROL REFLECTED IN EEG AND ERPS}

The central role of IFG/AI in switching between networks and exertion of top-down control (cf. Menon and Uddin, 2010) by coupling with areas such as STG appears to go together with synchronization of brain rhythms and generation of ERPs.

Midfrontal theta increase has been shown to predict post-error slowing (Cavanagh et al., 2009). Subjects with stronger medial frontal error-related theta also showed stronger white matter connectivity between the medial frontal theta source and the IFG and ventral striatum (Cohen, 2011). A correlation has been found between individual differences in post-error slowing and white matter integrity beneath dorsal ACC regions that are connected to the right IFG (Danielmeier et al., 2011). Similarly, inhibitionrelated increases in beta band power have been shown to relate to increased post-error slowing (Marco-Pallarés et al., 2008) and to right IFG activity through intracranial EEG recording (Swann et al., 2009). Top-down control from IFG/AI that increases processing in STS or visual cortices appears mediated by coherence in lowbeta (12-14 Hz; Frye et al., 2010) and alpha ranges (8-12 Hz; Zanto et al., 2010). An fMRI/EEG study found that theta-constrained fMRI activation was strongest in the insula, temporal pole, STG, and hippocampus (Sammer et al., 2007). Also alpha activity has been related to activity in the insula in studies combining EEG and fMRI measurements (Goldman et al., 2002; Martinez-Montes et al., 2004). Alpha activity related to activity in the insula, thalamus, and parieto-occipital cortex. The source reconstruction from the EEG spatial signature showed only the parieto-occipital sources, suggesting that the insula participates in the control of brain rhythms that it does not generate itself (Martinez-Montes et al., 2004). It can similarly be hypothesized that the IFG/AI participates in computations leading to ERP components, although it does not, or only to a small extent, participate in the actual generation of such components.

Even when other sources have been found also, the IFG/AI and STG have been linked to several ERPs. Different measuring techniques converge on the IFG and STS being involved in sensitivity of the N400 potential to semantic and emotional incongruency (Maess et al., 2006; Van Petten and Luka, 2006). During a switch task including a go-delay response condition that was performed in an fMRI and an ERP study, neither frontal N2 nor right IFG/AI activity were associated with either task set switching or response delaying per se. Instead, both were seen specifically for switching to a mode of response delaying (Swainson et al., 2003). The signal to switch from immediate to delayed responding may be similar to the signaling function of a perceived error during speeded response time tasks to delay the next response until processing of the erroneous trial is finished. Tomographical analyses of the $\mathrm{N} 2$ difference observed in conditions of equal go and no-go trial frequency localized N2 to the right IFG/AI and dorsolateral prefrontal cortex (Lavric et al., 2004). Error positivity (Pe) activity after about $300 \mathrm{~ms}$ that may relate to awareness of errors has been hypothesized to reflect activity in IFG/AI (Ullsperger et al., 2010). A recent MEG study found the late positive potential, which is sensitive to stimulus saliency, and Pe, to share similar STS sources (Helenius et al., 2010). The ventral cortical attentional saliency network involving IFG/AI, STG, temporo-parietal junction, and inferior parietal lobe, is sensitive to stimulus novelty and is the neural basis of the $\mathrm{P} 3$ potential response to novelty (e.g., Horn et al., 2003; Mulert et al., 2004; Gómez et al., 2008; Li et al., 2009), and fMRI regions that correlate with the amplitude of the P3 are insula, thalamus and right medial frontal gyrus (Horovitz et al., 2002). The stimulus-preceding anticipatory relatively rightlateralized negative potential that precedes aversive stimuli and feedback and seems to depend on its affective-motivational properties, was localized into the IFG/AI (Böcker et al., 1994; Lavric et al., 2008; Kotani et al., 2009; see also Brunia et al., 2000; Stern and Mangels, 2006). Interactions between the IFG/AI and STG have been implicated in the generation of the mismatch negativity (Opitz et al., 2002; Doeller et al., 2003). Occasional tone omissions elicited a significant increase in right STG activity $140 \mathrm{~ms}$ after the omitted stimulus, followed $60 \mathrm{~ms}$ later by right IFG activity (Tse et al., 2006). The functional relationship of STS and IFG is consistent with both the contrast enhancement and response inhibition accounts of IFG activity in passive deviance detection (Tse and Penney, 2008). Finally, face stimuli trigger a vertex positive potential (VPP, P150)/N170 component of the ERP. There is strong evidence that the fronto-central VPP and occipito-parietotemporal right-hemisphere-dominant N170 components can be accounted for by the same dipolar configuration, and the components show identical functional properties (Joyce and Rossion, 2005). The component has been source localized to the STS, with relative right lateralization (Itier and Taylor, 2004; Conty et al., 2007) as well as correlated with activity in the STS in a fMRI study (Horovitz et al., 2004).

\section{IFG/AI TOP-DOWN CONTROL REFLECTED IN ERROR-RELATED ERPS}

ERP studies have revealed a neural response to errors that has been termed the ERN or error negativity (Ne; Falkenstein et al., 1990; Gehring et al., 1990). The ERN/Ne is a negative ERP with a fronto-central scalp distribution, peaking 60-110 ms after an error response and is thought to be generated by the ACC.

The IFG/AI may also be involved in the occurrence of the ERN/Ne and Pe, ERP components that have been hypothesized to reflect partial phase-locking of intermittent theta-band EEG activity (Luu et al., 2004). The degree of right AI activation has been related to trait anxiety and the probability of selecting a "safe" response following a punished response (Paulus et al., 2003). A study that allowed subjects to reject trials to avoid errors, found error-specific responses only in bilateral AI (Magno et al., 2006). It is thought that the ERN/Ne is evoked by phasic reductions in DA striatal input in response to non-reward, i.e., "reward overprediction error" or "temporal difference prediction error." An fMRI study found that reward overprediction error produced decreased ventral striatal activation, consistent with prediction error theory; in addition, increased activation was found in the right IFG/AI and right ACC (Abler et al., 2005). Left IFG/AI were active during expectation of reward. The right AI has been shown to encode aversive cue-related prediction errors during Pavlovian learning 
of physical punishment (Seymour et al., 2004). Similarly, a recent pharmacological fMRI study showed that, during instrumental learning, reward prediction error was positively related to activity in the ventral striatum and posterior putamen, whereas during loss trials an aversive prediction error-related to activity in right AI (Pessiglione et al., 2006). Pharmacologically enhanced dopaminergic activity improved choice performance toward monetary gains but not avoidance of monetary losses, suggesting that the AI is involved in a non-dopaminergically modulated mechanism of aversive stimulus value processing during avoidance learning. A similar dissociation has been found between anticipatory ventral striatum activity related to subsequent financial risk taking and gain-seeking mistakes, vs. anticipatory AI activity related to subsequent risk avoidance and loss-aversion mistakes (Kuhnen and Knutson, 2005).

Indeed, the AI, together with the ACC, is the only prefrontal cortical area that densely projects to the striosomes in the striatum (Eblen and Graybiel, 1995) that are thought to be involved in reward prediction error calculations and the generation of the ERN/Ne in the ACC (Holroyd and Coles, 2002). Thus, neural activity in the IFG/AI could drive the activity of the mesolimbic dopamine system, which would then be reflected back to the ACC and other areas. Given the association of the ERN/Ne with punishment sensitivity, anxiety, and worry (see Boksem et al., 2006; Tops and Boksem, 2011), the focus in the literature on possible relationships between the ERN/Ne and reward prediction error but neglect of possible relationships with punishment prediction error is surprising. There appear to be physiological differences between selecting actions to achieve rewards and selecting actions to avoid losses (Pessiglione et al., 2006). Lesions involving the AI decrease or abolish ERN/Ne amplitude, and when involving the peri-insular white matter, disrupting connections to motor ACC, and the striatum, severely impair error corrections (Ullsperger and von Cramon, 2006).

To summarize, $\mathrm{fMRI}, \mathrm{EEG}$, and ERP studies converge on a role of IFG/AI in top-down control over motor as well as sensory areas.

\section{CONCLUSION}

We reviewed evidence for a model in which the IFG/AI is involved in elaborate attentional and working memory processing and we presented the hypothesis that this processing may take different forms and may have different effects, depending on the task at hand: (1) it may facilitate fast and accurate responding, or (2) it may cause slow responding when prolonged elaborate processing is required to increase accuracy of responding, or (3) it may interfere with accuracy and speed of next-trial (for instance, post-error) performance when prolonged elaborate processing interferes with processing of the next stimulus. We presented our

\section{REFERENCES}

Abler, B., Walter, H., and Erk, S. (2005). Neural correlates of frustration. Neuroreport 16, 669-672.

Aron, A. R. (2011). From reactive to proactive and selective control: developing a richer model for stopping inappropriate responses. Biol. Psychiatry 69, e55-e68.
Aron, A. R., Robbins, T. W., and Poldrack, R. A. (2004). Inhibition and the right inferior frontal cortex. Trends Cogn. Sci. (Regul. Ed.) 8, 170-177.

Assadollahi, R., and Rockstroh, B. S. (2008). Representation of the verb's argument-structure in the human brain. BMC Neurosci.

viewpoint that ventrolateral corticolimbic control pathways that include the IFG/AI, and mediodorsal corticolimbic control pathways that include dorsal ACC areas, are interacting but partly separable by their respective adaptations to environmental conditions that differ in the level of predictability (Tops et al., 2010). In the brain ventral corticolimbic control pathways have specialized in reactive behavioral control that incorporates fast associative learning that is adaptive in low-predictable environments. This contrasts to dorsal control pathways that specialized in guiding behavior proactively by context models in long-term memory that are formed and kept stable by slow learning, which is adaptive in high-predictable environments. The reactive systems produce a momentary, immediate sense of awareness, an experience of emotional stimuli as being close in time and space. In our opinion, both control pathways continued to develop during evolution, and both developed their own "cognitive controls," such that neither one can be properly described as purely "cognitive" nor "emotional." We speculate that IFG/AI may exert top-down control simultaneously over motor and sensory cortices to facilitate tight sensory guided feedback control of fine motoric ongoing actions in the context of a goal that is held active simultaneously (highconstraint control that may involve left hemisphere specialization; Tucker et al., 1995). Additionally, IFG/AI may facilitate sensory processing while preparing target-triggered responses, a type of control that may involve right hemisphere specialization. We discussed literature that suggests that IFG/AI function in top-down control modulates cortical rhythms and ERPs. Together, the literature suggests that the IFG/AI is an important node in brain networks that control cognitive and emotional processing and behavior.

Increasing attention to the role of IFG/AI in cognition and emotion could have important implications for research on mental health and psychopathology. For instance, the IFG/AI is among the areas that most consistently show increased activity related to anxiety and stress (see for a meta-analysis Etkin and Wager, 2007; for discussion Tops and Boksem, 2011). Also, antidepressant effects of medication and sleep deprivation were correlated with an activity shift from IFG/AI toward dorsolateral prefrontal cortex (Wu et al., 2008). A more global shift in activity from ventral toward dorsal cortical systems related to antidepressant effects has been discussed elsewhere, and may reflect difficulty to disengage from problems and rumination which goes at the expense of positive prospective and retrospective memory in depression (Tucker and Luu, 2007; Carver et al., 2008; Tops et al., 2010).

\section{ACKNOWLEDGMENTS}

This research was supported by a Veni grant of the Netherlands Organization for Scientific Research (NWO; 451-07-013).

9, 69. doi: 10.1186/1471-2202 9-69

Auksztulewicz, R., Spitzer, B., Goltz, D., and Blankenburg, F. (2011). Impairing somatosensory working memory using rTMS. Eur. J. Neurosci. 34, 839-844.

Baird, A., Dewar, B. K., Critchley, H., Gilbert, S. J., Dolan, R. J., and Cipolotti, L. (2006). Cognitive functioning after medial frontal lobe damage including the anterior cingulate cortex: a preliminary investigation. Brain Cogn. 60, 166-175.

Barbey, A. K., Krueger, F., and Grafman, J. (2009). An evolutionarily adaptive neural architecture for 
social reasoning. Trends Neurosci. 32, 603-610.

Bernal, B., and Altman, N. (2009). Neural networks of motor and cognitive inhibition are dissociated between brain hemispheres: an fMRI study. Int. J. Neurosci. 119, 1848-1880.

Böcker, K. B., Brunia, C. H., and van den Berg-Lenssen, M. M. (1994). A spatiotemporal dipole model of the stimulus preceding negativity (SPN) prior to feedback stimuli. Brain Topogr. 7, 71-88.

Boksem, M. A. S., Tops, M., Kostermans, E., and De Cremer, D. (2008). Sensitivity to punishment and reward omission: evidence from error-related ERP components. Biol. Psychol. 79, 185-192.

Boksem, M. A. S., Tops, M., Wester, A. E., Meijman, T. F., and Lorist, M. M. (2006). Error related ERP components, and individual differences in punishment, and reward sensitivity. Brain Res. 1101, 92-101.

Bossaerts, P. (2010). Risk and risk prediction error signals in anterior insula. Brain Struct. Funct. 214, 645-653.

Botvinick, M. M., Braver, T. S., Barch, D. M., Carter, C. S., and Cohen, J. D. (2001). Conflict monitoring and cognitive control. Psychol. Rev. 108, 624-652.

Bowlby, J. (1988). A Secure Base: ParentChild Attachment and Healthy Human Development. New York: Basic Books.

Brass, M., Derrfuss, J., Forstmann, B., and von Cramon, D. Y. (2005). The role of the inferior frontal junction area in cognitive control. Trends Cogn. Sci. (Regul. Ed.) 9, 314-316.

Braver, T. S., Paxton, J. L., Locke, H. S., and Barch, D. M. (2009). Flexible neural mechanisms of cognitive control within human prefrontal cortex. Proc. Natl. Acad. Sci. U.S.A. 106, 7351-7356.

Brunia, C. H., de Jong, B. M., van den Berg-Lenssen, M. M., and Paans, A. M. (2000). Visual feedback about time estimation is related to a right hemisphere activation measured by PET. Exp. Brain Res. 130, 328-337.

Bugg, J. M. (2008). Opposing influences on conflict-driven adaptation in the Eriksen flanker task. Mem. Cognit. 36, 1217-1227.

Bunge, S. A., Dudukovic, N. M., Thomason, M. E., Vaidya, C. J., and Gabrieli, J. D. (2002). Immature frontal lobe contributions to cognitive control in children: evidence from fMRI. Neuron 33, 301-311.

Bunge, S. A., Kahn, I., Wallis, J. D., Miller, E. K., and Wagner, A. D. (2003). Neural circuits subserving the retrieval and maintenance of abstract rules. J. Neurophysiol. 90, 3419-3428.

Carp, J., and Compton, R. J. (2009). Alpha power is influenced by performance errors. Psychophysiology 46, 336-343.

Carver, C. S., Johnson, S. L., and Joormann, J. (2008). Serotonergic function, two-mode models of self-regulation, and vulnerability to depression: what depression has in common with impulsive aggression. Psychol. Bull. 134, 912-943.

Carver, C. S., Johnson, S. L., and Joormann, J. (2009). Two-mode models of selfregulation as a tool for conceptualizing effects of the serotonin system in normal behavior and diverse disorders. Curr. Dir. Psychol. Sci. 18, 195-199.

Cauda, F., D’Agata, F., Sacco, K., Duca, S., Geminiani, G., and Vercelli, A. (2011). Functional connectivity of the insula in the resting brain. $\mathrm{Neu}$ roimage 55, 8-23.

Cavanagh, J. F., Cohen, M. X., and Allen, J. J. B. (2009). Prelude to and resolution of an error: EEG phase synchrony reveals cognitive control dynamics during action monitoring. J. Neurosci. 29, 98-105.

Chadick, J. Z., and Gazzaley, A. (2011). Differential coupling of visual cortex with default or frontal-parietal network based on goals. Nat. Neurosci. 14, 830-832.

Cohen, M. X. (2011). Error-related medial frontal theta activity predicts cingulate-related structural connectivity. Neuroimage 55, 1373-1383.

Compton, R. J., Arnstein, D., Freedman, G., Dainer-Best, J., and Liss, A. (2011). Cognitive control in the intertrial interval: evidence from EEG alpha power. Psychophysiology 48, 583-590.

Compton, R. J., Lin, M., Vargas, G., Carp, J., Fineman, S. L., and Quandt, L. C. (2008). Error detection and posterror behavior in depressed undergraduates. Emotion 8, 58-67.

Conty, L., N'Diaye, K., Tijus, C., and George, N. (2007). When eye creates the contact! ERP evidence for early dissociation between direct and averted gaze motion processing. Neuropsychologia 45, 3024-3037.

Craig, A. D. (2008). "Interoception and emotion: a neuroanatomical perspective," in Handbook of Emotions, 3rd Edn, eds M. Lewis, J. M. Haviland-Jones, and L. F. Barrett (New York: Guilford), 272-288

Craig, A. D. (2009). How do you feel now? The anterior insula and human awareness. Nat. Neurosci. 10, 59-70.

Craig, A. D. (2010). Once an island, now the focus of attention. Brain Struct. Funct. 214, 395-396.
Cromwell, H. C., and Panksepp, J. (2011). Rethinking the cognitive revolution from a neural perspective: how overuse/misuse of the term "cognition" and the neglect of affective controls in behavioral neuroscience could be delaying progress in understanding the brain mind. Neurosci Biobehav. Rev. 35, 2026-2035.

Danielmeier, C., Eichele, T., Forstmann, B. U., Tittgemeyer, M., and Ullsperger, M. (2011). Posterior medial frontal cortex activity predicts post-error adaptations in task-related visual and motor areas. J. Neurosci. 31, 1780-1789.

Danielmeier, C., and Ullsperger, M. (2011). Post-error adjustments. Front. Psychol. 2, 233. doi: 10.3389/fpsyg.2011.00233

Depue, B. E., Curran, T., and Banich, M. T. (2007). Prefrontal regions orchestrate suppression of emotional memories via a two-phase process. Science 317, 215-219.

Derryberry, D., and Tucker, D. M. (1994). "Motivating the focus of attention," in Heart's Eye: Emotional Influences in Perception and Attention, eds P. M. Niedenthal and S. Kitayama (New York, NY: Academic Press), 167-196.

di Pellegrino, G., Ciaramelli, E., and Làdavas, E. (2007). The regulation of cognitive control following rostral anterior cingulate cortex lesion in humans. J. Cogn. Neurosci. 19, 275-286.

Doeller, C. F., Opitz, B., Mecklinger, A., Krick, C., Reith, W., and Schröger, E. (2003). Prefrontal cortex involvement in preattentive auditory deviance detection: neuroimaging and electrophysiological evidence. Neuroimage 20, 1270-1282.

Dosenbach, N. U., Fair, D. A., Miezin, F. M., Cohen, A. L., Wenger, K. K., Dosenbach, R. A., Fox, M. D., Snyder, A. Z., Vincent, J. L., Raichle, M. E., Schlaggar, B. L., and Petersen, S. E. (2007). Distinct brain networks for adaptive and stable task control in humans. Proc. Natl. Acad. Sci. U.S.A 104, 11073-11078.

Dudschig, C., and Jentzsch, I. (2009). Speeding before and slowing after errors: is it all just strategy? Brain Res. 1296, 56-62.

Eblen, F., and Graybiel, A. M. (1995) Highly restricted origin of prefrontal cortical inputs to striosomes in the macaque monkey. J. Neurosci. 15, 5999-6013.

Eckert, M. A., Menon, V., Walczak, A., Ahlstrom, J., Denslow, S., Horwitz, A., and Dubno, J. R. (2009). At the heart of the ventral attention system: the right anterior insula. Hum. Brain Mapp. 30, 2530-2541.
Etkin, A., and Wager, T. D. (2007). Functional neuroimaging of anxiety: a meta-analysis of emotional processing in PTSD, social anxiety disorder, and specific phobia. Am. J. Psychiatry 164, 1476-1488.

Falkenstein, M., Hohnsbein, J., Hoormann, J., and Blanke, L. (1990). "Effects of errors in choice reaction tasks on the ERP under focused and divided attention," in Psychophysiological Brain Research, eds C. H. M. Brunia and A. W. K. Gaillard (Tilburg: Tilburg University Press), 192-195.

Fellows, L. K., and Farah, M. J. (2005). Is anterior cingulate cortex necessary for cognitive control? Brain 128, 788-796.

Flechsig, P. (1901). Developmental (myelogenetic) localisation of the cerebral cortex in the human subject. Lancet 2, 1027-1029.

Flechsig, P. (1920). Anatomie des Menschlichen Gehirnsund Ruckenmarks auf Myelogenetischer Grundlage. Leipzig: Thieme; New York: Basic Books.

Förster, J. (2009). Relations between perceptual and conceptual scope: how global versus local processing fits a focus on similarity versus dissimilarity. J. Exp. Psychol. Gen. 138, 88-111.

Fredrickson, B. L. (1998). What good are positive emotions? Rev. Gen. Psychol. 2, 300-319.

Friedman, R. S., and Förster, J. (2010). Implicit affective cues and attentional tuning: an integrative review. Psychol. Bull. 136, 875-893.

Friedman, R. S., and Förster, J. (2011). Limitations of the motivational intensity model of attentional tuning: reply to Harmon-Jones, Gable, and Price (2011). Psychol. Bull. 137, 513-516.

Frye, R. E., Wu, M.-H., Liederman, J., and McGraw Fisher, J. (2010). Greater pre-stimulus effective connectivity from the left inferior frontal area to other areas is associated with better phonological decoding in dyslexic readers. Front. Syst. Neurosci. 4:156. doi:10.3389/fnsys.2010.00156

Fuster, J. M. (1997). The Prefrontal Cortex: Anatomy, Physiology, and Neuropsychology of the Frontal Lobe. Philadelphia, PA: Lippincott-Raven.

Gable, P. A., and Harmon-Jones, E. (2008). Approach-motivated positive affect reduces breadth of attention. Psychol. Sci. 19, 476-482.

Gehring, W. J., Coles, M. G. H., Meyer, D. E., and Donchin, E. (1990). The error-related negativity: an eventrelated brain potential accompanying errors. Psychophysiology 27, S34. 
Goldman, R. I., Stern, J. M., Engel, J. Jr., and Cohen, M. S. (2002). Simultaneous EEG and fMRI of the alpha rhythm. Neuroreport 13, 2487-2492.

Gómez, C. M., Flores, A., and Digiacomo, M. R. (2008). Increased brain activation during the processing of spatially invalidly cued targets. Open Neuroimag. J. 2, 106-113.

Goodale, M. A., and Milner, A. D. (1992). Separate visual pathways for perception and action. Trends $\mathrm{Neu}$ rosci. 15, 20-25.

Grinband, J., Savitskaya, J., Wager, T. D., Teichert, T., Ferrera, V. P., and Hirsch, J. (2011). The dorsal medial frontal cortex is sensitive to time on task, not response conflict or error likelihood. Neuroimage 57, 303-311.

Gusnard, D. A., Ollinger, J. M., Shulman, G. L., Cloninger, C. R., Price, J. L., Van Essen, D. C., and Raichle, M. E. (2003). Persistence and brain circuitry. Proc. Natl. Acad. Sci. U.S.A. 100, 3479-3484.

Hampshire, A., Chamberlain, S. R., Monti, M. M., Duncan, J., and Owen, A. M. (2010). The role of the right inferior frontal gyrus: inhibition and attentional control. Neuroimage 50, 1313-1319.

Hampshire, A., Thompson, R., Duncan, J., and Owen, A. M. (2009). Selective tuning of the right inferior frontal gyrus during target detection. Cogn. Affect. Behav. Neurosci. 9, 103-112.

Harmon-Jones, C., Schmeichel, B. J., Mennitt, E., and Harmon-Jones, E. (2011a). The expression of determination: similarities between anger and approach-related positive affect. J. Pers. Soc. Psychol. 100, 172-181.

Harmon-Jones, E., Gable, P. A., and Price, T. F. (2011b). Toward an understanding of the influence of affective states on attentional tuning: comment on Friedman and Förster (2010). Psychol. Bull. 137, 508-512.

Harmon-Jones, E., and Gable, P. A. (2009). Neural activity underlying the effect of approach-motivated positive affect on narrowed attention. Psychol. Sci. 20, 406-409.

Heidbreder, C. A., and Groenewegen, H. J. (2003). The medial prefrontal cortex in the rat: evidence for a dorsoventral distinction based upon functional and anatomical characteristics. Neurosci. Biobehav. Rev. 27, 555-579.

Helenius, P., Laasonen, M., Hokkanen, L., Paetau, R., and Niemivirta, M. (2010). Neural correlates of late positivities associated with infrequent visual events and response errors. Neuroimage 53, 619-628.

Hester, R., Barre, N., Mattingley, J. B., Foxe, J. J., and Garavan, H. (2007). Avoiding another mistake: error and posterror neural activity associated with adaptive posterror behavior change. Cogn. Affect. Behav. Neurosci. 7, 317-326.

Higgins, E. T. (1997). Beyond pleasure and pain. Am. Psychol. 52, 1280-1300.

Higo, T., Mars, R. B., Boorman, E. D., Buch, E. R., and Rushworth, M. F. (2011). Distributed and causal influence of frontal operculum in task control. Proc. Natl. Acad. Sci. U.S.A. 108, 4230-4235.

Holroyd, C. B., and Coles, M. G. (2002). The neural basis of human error processing: reinforcement learning, dopamine, and the errorrelated negativity. Psychol. Rev. 109, 679-709.

Hommel, B., Kessler, K., Schmitz, F., Gross, J., Akyürek, E., Shapiro, K., and Schnitzler, A. (2006). How the brain blinks: towards a neurocognitive model of the attentional blink. Psychol. Res. 70, 425-435.

Horn, H., Syed, N., Lanfermann, H., Maurer, K., and Dierks, T. (2003) Cerebral networks linked to the event-related potential P300. Eur. Arch. Clin. Psychiatry Neurosci. 25, 154-159.

Horovitz, S. G., Rossion, B., Skudlarski, P., and Gore, J. C. (2004). Parametric design and correlational analyses help integrating fMRI and electrophysiological data during face processing. Neuroimage 22, 1587-1595.

Horovitz, S. G., Skudlarski, P., and Gore, J. C. (2002). Correlations and dissociations between BOLD signal and P300 amplitude in an auditory oddball task: a parametric approach to combining fMRI and ERP. Magn. Reson. Imaging 20, 319-325.

Ide, J. S., and Li, C. S. (2011). A cerebellar thalamic cortical circuit for error-related cognitive control. $\mathrm{Neu}$ roimage 54, 455-464.

Itier, R. J., and Taylor, M. J. (2004). Source analysis of the N170 to faces and objects. Neuroreport 15, 1261-1265.

Ivanoff, J., Branning, P., and Marois, R. (2008). fMRI evidence for a dual process account of the speed-accuracy tradeoff in decisionmaking. PLOS ONE 3, e2635. doi:10.1371/journal.pone.0002635

Jacobs, B. L., and Fornal, C. A. (1995). "Serotonin and behavior: a general hypothesis," in Psychopharmacology: The Fourth Generation of Progress, eds F. E. Bloom and D. J. Kupfer (New York: Raven Press), 461-469.

Jentzsch, I., and Leuthold, H. (2006). Control over speeded actions: a common processing locus for microand macro-trade-offs? Q. J. Exp. Psychol. (Hove). 59, 1329-1337.
Joyce, C., and Rossion, B. (2005). The face-sensitive N170 and VPP components manifest the same brain processes: the effect of reference electrode site. Clin. Neurophysiol. 116, 2613-2631.

Kennerley, S. W., Walton, M. E., Behrens, T. E., Buckley, M. J., and Rushworth, M. F. (2006). Optimal decision making and the anterior cingulate cortex. Nat. Neurosci. 9, 940-947.

King, J. A., Korb, F. M., von Cramon, D. Y., and Ullsperger, M. (2010). Post-error behavioral adjustments are facilitated by activation and suppression of task-relevant and taskirrelevant information processing. $J$. Neurosci. 30, 12759-12769.

Kotani, Y., Ohgami, Y., Kuramoto, Y., Tsukamoto, T., Inoue, Y., and Aihara, Y. (2009). The role of the right anterior insular cortex in the right hemisphere preponderance of stimuluspreceding negativity (SPN): an fMRI study. Neurosci. Lett. 450, 75-79.

Kouneiher, F., Charron, S., and Koechlin, E. (2009). Motivation and cognitive control in the human prefronta cortex. Nat. Neurosci. 12, 939-945.

Kuhnen, C. M., and Knutson, B. (2005) The neural basis of financial risk taking. Neuron 47, 763-770.

Langens, T. A. (2007). Regulatory focus and illusions of control. Pers. Soc. Psychol. Bull. 33, 226-237.

Lavric, A., Mizon, G. A., and Monsell, S. (2008). Neurophysiological signature of effective anticipatory task-set control: a task-switching investigation. Eur. J. Neurosci. 28, 1016-1029.

Lavric, A., Pizzagalli, D. A., and Forstmeier, S. (2004). When "go" and "nogo" are equally frequent: ERP components and cortical tomography. Eur. J. Neurosci. 20, 2483-2488.

Leitman, D. I., Wolf, D. H., Ragland, J. D., Laukka, P., Loughead, J., Valdez, J. N., Javitt, D. C., Turetsky, B. I., and Gur, R. C. (2010). "It's not what you say, but how you say it": a reciprocal temporofrontal network for affective prosody. Front. Hum. Neurosci. 4:19. doi:10.3389/fnhum.2010.00019

Li, C. S., Huang, C., Yan, P., Paliwal, P., Constable, R. T., and Sinha, R. (2008). Neural correlates of posterror slowing during a stop signal task: a functional magnetic resonance imaging study. J. Cogn. Neurosci. 20, 1021-1029.

Li, Y., Wang, L. Q., and Hu, Y. (2009). Localizing P300 generators in highdensity event- related potential with fMRI. Med. Sci. Monit. 15, MT47MT53.

Liberman, N., and Förster, J. (2009). Distancing from experienced self: how global-versus-local perception affects estimation of psychological distance. J. Pers. Soc. Psychol. 97, 203-216.

Luu, P., Tucker, D. M., and Derryberry, D. (1998). Anxiety and the motivational basis of working memory. Cogn. Ther. Res. 22, 577-594.

Luu, P., Tucker, D. M., and Makeig, S. (2004). Frontal midline theta and the error-related negativity: neurophysiological mechanisms of action regulation. Clin. Neurophysiol. 115, 1821-1835.

Maess, B., Herrmann, C. S., Hahne, A., Nakamura, A., and Friederici, A. D. (2006). Localizing the distributed language network responsible for the N400 measured by MEG during auditory sentence processing. Brain Res. 1096, 163-172.

Magno, E., Foxe, J. J., Molholm, S., Robertson, I. H., and Caravan, $\mathrm{H}$. (2006). The anterior cingulate and error avoidance. J. Neurosci. 26, 4769-4773.

Marco-Pallarés, J., Camara, E., Münte, T. F., and Rodríguez-Fornells, A (2008). Neural mechanisms underlying adaptive actions after slips. $J$. Cogn. Neurosci. 20, 1595-1610.

Martinez-Montes, E., Valdes-Sosa, P. A. Miwakeichi, F., Goldman, R. I., and Cohen, M. S. (2004). Concurrent EEG/fMRI analysis by multiway partial least squares. Neuroimage 22, 1023-1034.

McNab, F., Leroux, G., Strand, F., Thorell, L., Bergman, S., and Klingberg, T. (2008). Common and unique components of inhibition and working memory: an fMRI, within-subjects investigation. $\mathrm{Neu}$ ropsychologia 46, 2668-2682.

Melcher, T., and Gruber, O. (2008). Decomposing interference during Stroop performance into different conflict factors: an event-related fMRI study. Cortex 45, 189-200.

Menon, V., and Uddin, L. Q. (2010). Saliency, switching, attention and control: a network model of insula function. Brain Struct. Funct. 214, 655-667.

Molenberghs, P., Gillebert, C. R., Schoofs, H., Dupont, P., Peeters, R., and Vandenberghe, R. (2009). Lesion neuroanatomy of the sustained attention to response task. Neuropsychologia 47, 2866-2875.

Mulert, C., Pogarell, O., Juckel, G., Rujescu, D., Giegling, I., Rupp, D., Mavrogiorgou, P., Bussfeld, P., Gallinat, J., Möller, H. J., and Hegerl, U. (2004). The neural basis of the P300 potential. Focus on the time-course of the underlying cortical generators. Eur. Arch. Psychiatry Clin. Neurosci. 254, 190-198. 
Nee, D. E., Wager, T. D., and Jonides, J. (2007). Interference resolution: insights from a meta-analysis of neuroimaging tasks. Cogn. Affect. Behav. Neurosci. 7, 1-17.

Nelson, S. M., Dosenbach, N. U., Cohen, A. L., Wheeler, M. E., Schlaggar, B. L., and Petersen, S. E. (2010). Role of the anterior insula in task-level control and focal attention. Brain Struct. Funct. 214, 669-680.

Notebaert, W., Houtman, F., Opstal, F. V., Gevers, W., Fias, W., and Verguts, T. (2009). Post-error slowing: an orienting account. Cognition 111, 275-279.

Opitz, B., Rinne, T., Mecklinger, A., von Cramon, D. Y., and Schröger, E. (2002). Differential contribution of frontal and temporal cortices to auditory change detection: fMRI and ERP results. Neuroimage 15, 167-174.

O'Reilly, R. C. (2010). The what and how of prefrontal cortical organization. Trends Neurosci. 33, 355-361.

Owen, A. M. (2000). The role of the lateral frontal cortex in mnemonic processing: the contribution of functional neuroimaging. Exp. Brain Res. 133, 33-43.

Paulus, M. P., Rogalsky, C., Simmons, A., Feinstein, J. S., and Stein, M. B. (2003). Increased activation in the right insula during risk-taking decision making is related to harm avoidance and neuroticism. Neuroimage 19, 1439-1448.

Paulus, M. P., and Stein, M. B. (2006). An insular view of anxiety. Biol. Psychiatry 60, 383-387.

Pessiglione, M., Seymour, B., Flandin, G., Dolan, R. J., and Frith, C. D. (2006). Dopamine-dependent prediction errors underpin rewardseeking behavior inhumans. Nature 442, 1042-1045.

Phaf, R. H., and Kan, K. J. (2007). The automaticity of emotional Stroop: a meta-analysis. J. Behav. Ther. Exp. Psychiatry 38, 184-199.

Sakagami, M., Pan, X., and Uttl, B. (2006). Behavioral inhibition and prefrontal cortex in decision-making. Neural Netw. 19, 1255-1265.

Sammer, G., Blecker, C., Gebhardt, H., Bischoff, M., Stark, R., Morgen, K., and Vaitl, D. (2007). Relationship between regional hemodynamic activity and simultaneously recorded EEG-theta associated with mental arithmeticinduced workload. Hum. Brain Mapp. 28, 793-803.
Schiff, B. B., Guirguis, M., Kenwood, C., and Herman, C. P. (1998). Asymmetrical hemispheric activation and behavioral persistence: effects of unilateral muscle contractions. Neuropsychology 12, 526-532.

Schwarz, N. (1990). "Feelings as information: informational and motivational functions of affective states," in Handbook of Motivation and Cognition: Foundations of Social Behavior, Vol. 2, eds E. T. Higgins and R. M. Sorrentino (New York, NY: Guilford Press), 527-561.

Seymour, B., O’Doherty, J. P., Dayan, P., Koltzenburg, M., Jones, A. K., Dolan, R. J., Friston, K. J., and Frackowiak, R. S. (2004). Temporal difference models describe higher-order learning in humans. Nature 429, 664-667.

Simmons, A., Strigo, I., Matthews, S. C., Paulus, M. P., and Stein, M. B. (2006). Anticipation of aversive visual stimuli is associated with increased insula activation in anxiety-prone subjects. Biol. Psychiatry 60, 402-409.

Sridharan, D., Levitin, D. J., and Menon, V. (2008). A critical role for the right fronto-insular cortex in switching between central-executive and default-mode networks. Proc. Natl. Acad. Sci. U.S.A. 105, 12569-12574.

Stern, E. R., and Mangels, J. A. (2006). An electrophysiological investigation of preparatory attentional control in a spatial Stroop task. J. Cogn. Neurosci. 18, 1004-1017.

Stuss, D. T., and Alexander, M. P. (2007). Is there a dysexecutive syndrome? Philos. Trans. R. Soc. Lond. B Biol. Sci. 362, 901-915.

Swainson, R., Cunnington, R., Jackson, G. M., Rorden, C., Peters, A. M., Morris, P. G., and Jackson, S. R. (2003). Cognitive control mechanisms revealed by ERP and $\mathrm{AMRI}$ : evidence from repeated task-switching. J. Cogn. Neurosci. 15, 785-799.

Swann, N., Tandon, N., Canolty, R., Ellmore, T. M., McEvoy, L. K., Dreyer, S., DiSano, M., and Aron, A. R. (2009). Intracranial EEG reveals a time- and frequency-specific role for the right inferior frontal gyrus and primary motor cortex in stopping initiated responses. J. Neurosci. 29 12675-12685.

Thayer, R. E. (1989). The Biopsychology of Mood and Arousal. New York: Oxford.

Tops, M. (2004). Inhibition of Approach: Cortisol-mediated Mechanisms in
Affect and Depression, Doctoral thesis, University of Groningen, Groningen.

Tops, M., and Boksem, M. A. S. (2010). Absorbed in the task: personality measures predict engagement during task performance as tracked by error negativity and asymmetrical frontal activity. Cogn. Affect. Behav. Neurosci. 10, 441-453.

Tops, M., and Boksem, M. A. S. (2011). Cortisol involvement in mechanisms of behavioral inhibition. Psychophysiology 48, 723-732.

Tops, M., Boksem, M. A. S., Luu, P., and Tucker, D. M. (2010) Brain substrates of behavioral programs associated with selfregulation. Front. Psychol. 1:152. doi:10.3389/fpsyg.2010.00152

Tops, M., Boksem, M. A. S., Wester, A. E., Lorist, M. M., and Meijman, T. F. (2006). Task engagement and the relationships between the error-related negativity, agreeableness, behavioral shame proneness and cortisol. Psychoneuroendocrinology 31, 847-858.

Tops, M., and de Jong, R. (2006). Posing for success: clenching a fist facilitates approach. Psychon. Bull. Rev. 13, 229-234.

Tse, C. Y., and Penney, T. B. (2008). On the functional role of temporal and frontal cortex activation in passive detection of auditory deviance. Neuroimage 41, 1462-1470.

Tse, C. Y., Tien, K. R., and Penney, T. B. (2006). Event-related optical imaging reveals the temporal dynamics of right temporal and frontal cortex activation in pre-attentive change detection. Neuroimage 29, 314-320.

Tucker, D. M., and Luu, P. (2007). Neurophysiology of motivated learning: adaptive mechanisms of cognitive bias in depression. Cogn. Ther. Res. 31, 189-209.

Tucker, D. M., Luu, P., Frishkoff, G. Quiring, J., and Poulsen, C. (2003). Frontolimbic response to negative feedback in clinical depression. $J$. Abnorm. Psychol. 112, 667-678.

Tucker, D. M., Luu, P., and Pribram, K. H. (1995). Social and emotional selfregulation. Ann. N. Y. Acad. Sci. 769, 213-239.

Tucker, D. M., and Williamson, P. A. (1984). Asymmetric neural control systems in human self-regulation. Psychol. Rev. 91, 185-215.

Tyler, S. K., and Tucker, D. M. (1982). Anxiety and perceptual structure: individual differences in neuropsychological function. J. Abnorm. Psychol. 91, 210-220.
Ullsperger, M., Bylsma, L. M., and Botvinick, M. M. (2005). The conflict adaptation effect: it's not just priming. Cogn. Affect. Behav. Neurosci. 5, 467-472.

Ullsperger, M., Harsay, H. A., Wessel, J. R., and Ridderinkhof, K. R. (2010). Conscious perception of errors and its relation to the anterior insula. Brain Struct. Funct. 214, 629-643.

Ullsperger, M., and von Cramon, D. Y. (2006). The role of intact frontostriatal circuits in error processing. J. Cogn. Neurosci. 18, 651-664.

Van Petten, C., and Luka, B. J. (2006). Neural localization of semantic context effects in electromagnetic and hemodynamic studies. Brain Lang. 97, 279-293.

Verbruggen, F., Aron, A. R., Stevens, M. A., and Chambers, C. D. (2010). Theta burst stimulation dissociates attention and action updating in human inferior frontal cortex. Proc. Natl. Acad. Sci. U.S.A. 107, 13966-13971.

Verguts, T., Notebaert, W., Kunde, W., and Wühr, P. (2011). Post-conflict slowing: cognitive adaptation after conflict processing. Psychon. Bull. Rev. 18, 76-82.

Wager, T. D., Davidson, M. L., Hughes, B. L., Lindquist, M. A., and Ochsner, K. N. (2008). Prefrontal-subcortical pathways mediating successful emotion regulation. Neuron 59, $1037-$ 1050.

Wager, T. D., Sylvester, C. Y., Lacey, S. C., Nee, D. E., Franklin, M., and Jonides, J. (2005). Common and unique components of response inhibition revealed by fMRI. Neuroimage 27, 323-340.

Whittle, S., Allen, N. B., Lubman, D. I., and Yücel, M. (2006). The neurobiological basis of temperament: towards a better understanding of psychopathology. Neurosci. Biobehav. Rev. 30, 511-525.

Wittfoth, M., Küstermann, E., Fahle, M., and Herrmann, M. (2008). The influence of response conflict on error processing: evidence from event-related fMRI. Brain Res. 1194, 118-129.

Wu, J. C., Gillin, J. C., Buchsbaum, M. S., Schachat, C., Darnall, L. A. Keator, D. B., Fallon, J. H., and Bunney, W. E. (2008). Sleep deprivation PET correlations of Hamilton symptom improvement ratings with changes in relative glucose metabolism in patients with depression. J. Affect. Disord. 107, 181-186. 
Wylie, S. A., van den Wildenberg, W. P., Ridderinkhof, K. R., Bashore, T. R., Powell, V. D., Manning, C. A., and Wooten, G. F. (2009). The effect of speed-accuracy strategy on response interference control in Parkinson's disease. Neuropsychologia 47, 1844-1853.

Yeung, N., Cohen, J. D., and Botvinick, M. M. (2011). Errors of interpretation and modeling: a reply to Grinband et al.
Neuroimage 57, 316-319; discussion 320-322.

Zanto, T. P., Rubens, M. T., Bollinger, J., and Gazzaley, A. (2010). Topdown modulation of visual feature processing: the role of the inferior frontal junction. Neuroimage 53, 736-745.

Conflict of Interest Statement: The authors declare that the research was conducted in the absence of any commercial or financial relationships that could be construed as a potential conflict of interest.

Received: 09 July 2011; accepted: 25 October 2011; published online: 10 November 2011.

Citation: Tops $M$ and Boksem MAS (2011) A potential role of the inferior frontal gyrus and anterior insula in cognitive control, brain rhythms, and eventrelated potentials. Front. Psychology
2:330. doi: 10.3389/fpsyg.2011.00330 This article was submitted to Frontier in Cognition, a specialty of Frontiers in Psychology.

Copyright $(\odot 2011$ Tops and Boksem. This is an open-access article subject to a nonexclusive license between the authors and Frontiers Media SA, which permits use, distribution and reproduction in other forums, provided the original authors and source are credited and other Frontiers conditions are complied with. 